\title{
Insulin-like growth factor binding protein-1 as a predictor of glucose-stimulated hyperinsulinemia in prepubertal obese children
}

\author{
Hisako Saitoh, Tomohiro Kamoda, Satoko Nakahara ${ }^{1}$, Takeki Hirano ${ }^{2}$ and Akira Matsui \\ Department of Pediatrics, University of Tsukuba, Tsukuba, Japan, ${ }^{1}$ Department of Pediatrics, Kensei General Hospital, Iwase, Japan and ${ }^{2}$ Department of \\ Pediatrics, Ibaraki Children's Hospital, Ibaraki, Japan
}

(Correspondence should be addressed to T Kamoda, Department of Pediatrics, Institute of Clinical Medicine, University of Tsukuba, 1-1-1 Tennoudai, Tsukuba 305, Ibaraki, Japan)

\begin{abstract}
Objective: The present study was undertaken to examine the association of a glucose-stimulated insulin response with the fasting insulin-like growth factor-binding protein (IGFBP)-1 concentration in prepubertal obese children.

Subjects and methods: The fasting levels of serum insulin and IGFBP-1 were measured in 17 obese and 16 control children. Furthermore, we performed an oral glucose tolerance test in obese children and examined the association of the area under the curve (AUC) for insulin with the fasting IGFBP-1 level. Results: The mean serum level of IGFBP-1 was significantly lower in obese children $(41.0 \pm 4.8 \mu \mathrm{g} / \mathrm{l}$, $P<0.005)$ than in controls $(91.2 \pm 9.9 \mu \mathrm{g} / \mathrm{l})$. Although there was an inverse relationship between the fasting levels of serum insulin and IGFBP-1 in all subjects $(r=-0.42, P<0.05)$, no significant correlation between these two parameters was observed in the obese group alone. In obese children, the fasting IGFBP-1 level correlated inversely with AUC-insulin $(r=-0.70, P<0.005)$, whereas there was no significant relationship between the fasting insulin level and AUC-insulin.

Conclusion: The present study suggests that the serum level of IGFBP-1 may be an early predictor of insulin resistance in prepubertal obesity.
\end{abstract}

European Journal of Endocrinology 140 231-234

\section{Introduction}

It is well known that the fasting plasma level of insulin is significantly higher in obese children compared with non-obese children and it is one of the most useful indices for predicting the development of obesityassociated complications such as non-insulin dependent diabetes mellitus, hypertension and hyperlipidemia (1). However, prepubertal obese children do not always show fasting hyperinsulinemia as found in adult obesity, because such hyperinsulinism may not become manifest until a later age (2).

On the other hand, insulin-like growth factor (IGF)binding protein (IGFBP)-1 is believed to play an important role in glucose regulation and is regulated directly by insulin, which suppresses IGFBP-1 production in the liver (3). In obese subjects, the serum IGFBP1 level was low and correlated inversely with serum insulin (4). Recently, Mogul et al. (5) have demonstrated that the fasting level of IGFBP-1 is a useful marker of the future development of diabetes in obese adults. We have also reported that the serum IGFBP-1 level is suppressed in prepubertal obese children with fasting normoinsulinemia, suggesting that the reduced IGFBP-1 level may reflect potential hyperinsulinemia (6). The objective of this study was to examine the association of a glucosestimulated insulin response with the fasting IGFBP-1 level in prepubertal obese children.

\section{Subjects and methods}

\section{Subjects}

Seventeen Japanese children with simple obesity and 16 control children matched for age, sex and pubertal stage were included in the study. The control children were selected from the patients visiting the pediatric clinic because of non-endocrinological problems. None of the controls had a family history of obesity or diabetes. The obese subjects were chosen from all children newly diagnosed as having simple obesity at the pediatric clinic of Tsukuba University Hospital. The characteristics of the subjects are shown in Table 1. Both obese and control children were prepubertal (Tanner stage 1). Boys had testes volumes less than $4 \mathrm{ml}$, and pubic hair stage P1. No breast or pubic hair development was seen in girls. The obese children, who weighed $20 \%$ or more 
Table 1 Characteristics of obese and control children. Values are means \pm S.E.M. with the ranges in parentheses.

\begin{tabular}{lcc}
\hline & $\begin{array}{c}\text { Obese } \\
(n=17)\end{array}$ & $\begin{array}{c}\text { Control } \\
(n=16)\end{array}$ \\
\hline Age (years) & $8.3 \pm 0.3$ & $8.3 \pm 0.6$ \\
Sex (M:F) & $(6.3-10.2)$ & $(6.6-11.1)$ \\
BMI (kg/m $\left.{ }^{2}\right)$ & $9: 8$ & $9: 7$ \\
& $25.3 \pm 0.7$ & $16.1 \pm 0.4$ \\
Ideal body weight (\%) & $(20.3-33.8)$ & $(14.0-19.3)$ \\
& $156.9 \pm 4.0$ & $100.5 \pm 2.6$ \\
& $(130.8-198.9)$ & $(80.0-118.0)$ \\
\hline
\end{tabular}

$\mathrm{BMI}=$ body mass index.

above the expected weight for age, sex and height, were diagnosed as having simple obesity with the absence of genetic or endocrinological abnormalities. With growth curve charts recorded from the children's birth, the onset of obesity was dated from when the patient fulfilled the criteria for simple obesity mentioned above. The mean ( \pm S.E.M.) duration of obesity in the children studied was $5.1 \pm 0.4$ years. The obese children were all free of clinically or biochemically apparent disease other than obesity and were not taking any medication. Informed consent was obtained from the parents of all the children and the study was approved by the local ethics committee.

\section{Methods}

An oral glucose tolerance test (OGTT: $1.75 \mathrm{~g}$ glucose $/ \mathrm{kg}$ body weight; maximum, $75 \mathrm{~g}$ ) was performed after an overnight fast in obese children. Blood samples were obtained to assay blood glucose and serum insulin in the fasting state and 30, 60, 90 and $120 \mathrm{~min}$ after glucose intake. All obese children had normal glucose tolerance (7). The serum insulin was also measured in controls. IGFBP-1 assays were performed on fasting serum samples in both obese and control subjects. The glucosestimulated area under the curve (AUC) for insulin in the OGTT was calculated using the following published formula (8): Area $=0.25$ (fasting value $)+0.5(0.5 \mathrm{~h}$ value $)+$ $0.75(1 \mathrm{~h}$ value $)+0.5(2 \mathrm{~h}$ value $)$.

\section{Hormone assays}

The serum insulin level was determined with an RIA kit (Diagnostic Products Co., CA, USA), with inter- and intra-assay coefficients of variation of $4.9-10 \%$ and $2.5-6.5 \%$ respectively, and a lower detection limit of $6 \mathrm{pmol} / \mathrm{l}$. Serum IGFBP-1 was determined with an RIA kit (Diagnostic System Laboratories, Inc., TX, USA) which is not affected by the state of IGFBP-1 phosphorylation and quantifies total IGFBP-1 in serum. The lower detection limit was $0.33 \mu \mathrm{g} / \mathrm{l}$ and inter- and intra-assay coefficients of variation were $3.5-6.0 \%$ and $2.7-5.2 \%$ respectively.

\section{Statistical analysis}

All results were expressed as means \pm s.E.M. unless otherwise stated. Student's unpaired $t$-test or the Mann-Whitney U test was used to determine statistical significance. Relationships between parameters were evaluated by linear regression analysis. All analyses were performed using Stat View 4.02 software (Abacus Concepts, Inc., CA, USA). Statistical significance was defined as a $P$ value of less than 0.05 .

\section{Results}

The fasting level of insulin was significantly higher in obese subjects $(62.5 \pm 8.0 \mathrm{pmol} / \mathrm{l}, P<0.005)$ than in controls $(34.5 \pm 4.1 \mathrm{pmol} / \mathrm{l}$; Table 2$)$. In contrast, the serum level of IGFBP-1 was significantly lower in obese subjects $(41.0 \pm 4.8 \mu \mathrm{g} / \mathrm{l}, P<0.005)$ than in controls $(91.2 \pm 9.9 \mu \mathrm{g} / \mathrm{l}$; Table 2). The mean AUC-insulin level in the obese group was $629.1 \pm 62.1 \mathrm{pmol} / \mathrm{l}$.

Although there was an inverse relationship between the fasting levels of serum insulin and IGFBP-1 in all subjects $(r=-0.42, P<0.05$; Fig. 1$)$, no significant correlation between these two parameters was observed in the obese group alone $(r=-0.17, P=0.52)$. In obese children, the fasting IGFBP-1 level correlated inversely with AUC-insulin ( $r=-0.70, P<0.005$; Fig. 2), whereas there was no significant relationship between the fasting insulin level and AUC-insulin $(r=0.31, P=0.22)$.

The mean ( \pm s.D.) concentration of fasting serum insulin in control children was $34.5 \pm 16.6 \mathrm{pmol} / \mathrm{l}$. Using the mean+2s.D. $(67.7 \mathrm{pmol} / \mathrm{l})$ of the fasting insulin in controls as a cut-off point, we divided the obese subjects into two groups. Twelve out of 17 obese children were considered to be normoinsulinemic in the fasting state, their IGFBP-1 levels remaining significantly low $(42.4 \pm 6.5 \mu \mathrm{g} / \mathrm{l}, \quad P<0.01)$ compared with those in controls.

\section{Discussion}

We selected prepubertal children for the present study, because several studies had demonstrated that puberty was associated with decreased insulin sensitivity (9, 10). Traverse et al. (11) showed that the pubertal changes in insulin sensitivity were related to changes in body composition. Additionally, by studying prepubertal children it is possible to eliminate the confounding

Table 2 Mean serum concentrations of insulin and IGFBP-1 in obese and control children. Values are means \pm S.E.M.

\begin{tabular}{lccc}
\hline & $\begin{array}{c}\text { Obese } \\
(n=17)\end{array}$ & $\begin{array}{c}\text { Control } \\
(n=16)\end{array}$ & $P$ value \\
\hline Insulin $(\mathrm{pmol} / \mathrm{l})$ & $62.5 \pm 8.0$ & $34.5 \pm 4.1$ & $<0.005$ \\
IGFBP-1 $(\mu \mathrm{g} / \mathrm{l})$ & $41.0 \pm 4.8$ & $91.2 \pm 9.9$ & $<0.005$ \\
\hline
\end{tabular}




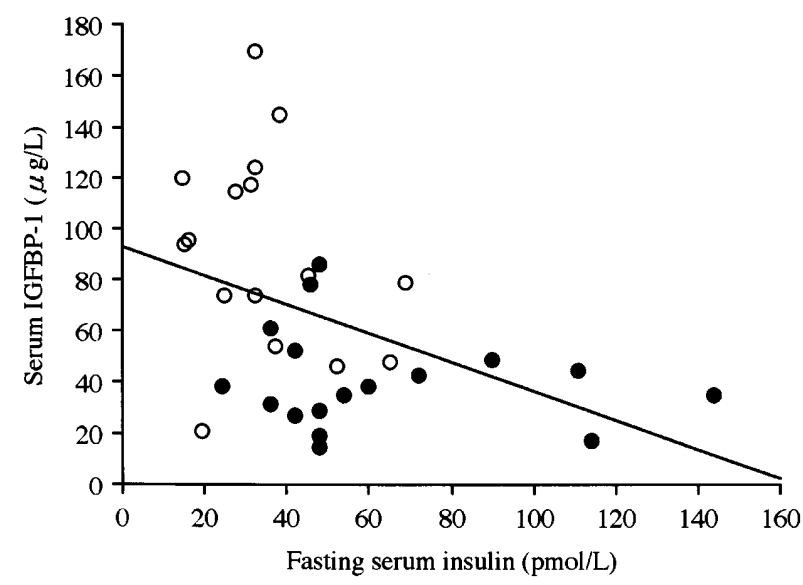

Figure 1 Relationship between fasting levels of serum insulin and IGFBP-1 in control $(O)$ and obese $(\bullet)$ children $(r=-0.42, P<0.05)$.

hormonal and metabolic effects of puberty per se on insulin action and secretion.

IGFBP-1, a peptide predominantly of hepatic origin, is one of six binding proteins which regulate IGF-I bioavailability, and is believed to play an important role in glucose counter-regulation (12). The serum level of IGFBP-1 is regulated directly by insulin, which suppresses IGFBP-1 production in the liver (3). Conover et al. (4) showed that the serum IGFBP-1 level was low and correlated inversely with the serum level of insulin in obese adults. We also observed the decreased level of IGFBP-1 in prepubertal obese children with fasting normoinsulinemia. However, the low level of IGFBP-1 could not be explained by the fasting insulin level alone, since no inverse correlation existed between these two parameters in the study. Brismar et al. (13) reported that no correlation was found between basal levels of insulin and IGFBP-1 in non-obese healthy adults, but the basal IGFBP-1 level correlated inversely with the integrated $2 \mathrm{~h}$ insulin release during the hyperglycemic clamp. We

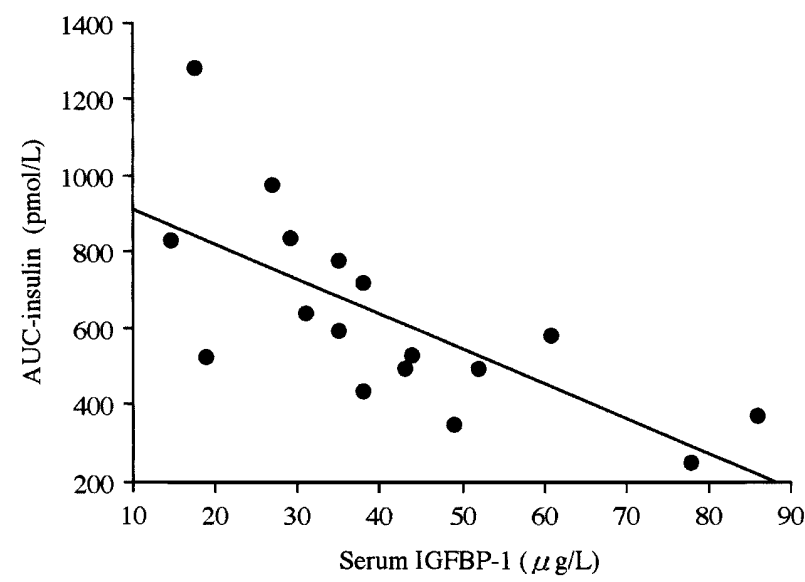

Figure 2 Relationship between fasting IGFBP-1 levels and AUCinsulin in obese children $(r=-0.70, P<0.005)$. therefore hypothesized that the hyperinsulinemia which could not be detected in the fasting state might have suppressed hepatic production of IGFBP-1. Thus, we performed an OGTT to examine the association of a glucose-stimulated insulin response with the fasting IGFBP-1 level in obese children. Consequently, in obese children, the fasting IGFBP-1 level correlated inversely with AUC-insulin, whereas there was no significant relationship between fasting insulin and AUC-insulin. Therefore, it is suggested that the fasting IGFBP-1 may be a better predictor of AUC-insulin than the fasting insulin. This finding is similar to the previous report by Hellénius et al. (14), who showed that the basal IGFBP-1 level correlated inversely with AUC-insulin in normoglycemic healthy men. Furthermore, Mogul et al. (5) also demonstrated that the fasting level of IGFBP-1 was a useful marker of the future development of diabetes in obese menopausal women.

Since no OGTT was performed in our control children, we could not determine whether the AUCinsulin level was abnormally high in obese children compared with controls. However, several studies have demonstrated a hyperresponse of insulin to glucose in obese subjects regardless of the fasting insulin level. Le Stunff \& Bougnères (2) studied the development of hyperinsulinemia in obese children with a recent onset of obesity, and showed that postprandial hypersecretion of insulin was one of the earliest metabolic alterations, followed by fasting hyperinsulinemia. Similarly, Reaven et al. (15) reported that moderately obese adults with normal glucose tolerance and fasting normoinsulinemia have an exaggerated insulin response to OGTT compared with the non-obese individuals. Thus, it is conceivable that the AUC-insulin level in OGTT is increased in our obese children, which in turn may reflect the decreased IGFBP-1 level.

Brismar et al. (13) investigated a role of insulin in the regulation of IGFBP-1 in healthy adults, who were classified as high insulin responders or low insulin responders on the basis of their insulin response to a standardized glucose infusion test, and showed that the fasting level of IGFBP-1 was significantly lower in high insulin responders than in low insulin responders, although the fasting insulin level did not differ between the two groups. Furthermore, they demonstrated that the fasting level of IGFBP-1 correlated inversely with the integrated insulin and positively with insulin sensitivity, whereas it did not correlate with the fasting insulin level (13). In addition, Morris \& Falcone (16) showed that, in women with polycystic ovary syndrome, both insulin sensitivity and the IGFBP-1 level were significantly lower than in controls and the IGFBP-1 level correlated positively with insulin sensitivity. Therefore, the reduced IGFBP-1 level may be explained by impaired insulin sensitivity and may predict insulin resistance in obese subjects. In our study, the serum level of IGFBP-1 was significantly decreased even in the obese children with fasting normoinsulinemia, suggesting that impaired 
insulin sensitivity had already developed. Since it is difficult and time consuming to evaluate insulin resistance by an OGTT in prepubertal children, a single measurement of IGFBP-1 may be a better method for screening potential insulin resistance. Alternatively, the reduced level of IGFBP-1 allows greater fractions of IGF-I to be unbound and increases the tissue availability of IGF-I, which in turn stimulates glucose uptake in patients with impaired insulin sensitivity. Therefore, the low IGFBP-1 level may be a compensatory response to decreased insulin sensitivity.

In conclusion, our results suggest that the fasting level of IGFBP-1 may be a useful predictor for early identification of the development of insulin resistance in prepubertal obese children.

\section{References}

1 Waliul Islam AHM, Yamashita S, Kotani K, Nakamura T, Tokunaga K, Arai $\mathrm{T}$ et al. Fasting plasma insulin level is an important risk factor for the development of complications in Japanese obese children. Metabolism 199544 478-485.

2 Le Stunff C \& Bougnères P. Early changes in postprandial insulin secretion, not in insulin sensitivity, characterize juvenile obesity. Diabetes 199443 696-702.

3 Brismar K, Fernqvist-Forbes E, Wahren J \& Hall K. Effect of insulin on the hepatic production of insulin-like growth factor-binding protein-1 (IGFBP-1), IGFBP-3, and IGF-I in insulin-dependent diabetes. Journal of Clinical Endocrinology and Metabolism 199479 $872-878$.

4 Conover CA, Lee PDK, Kanaley JA, Clarkson JT \& Jensen MD. Insulin regulation of insulin-like growth factor binding protein-1 in obese and nonobese humans. Journal of Clinical Endocrinology and Metabolism 199274 1355-1360.

5 Mogul HR, Marshall M, Frey M, Burke HB, Wynn PS, Wilker S et al. Insulin like growth factor-binding protein-1 as a marker for hyperinsulinemia in obese menopausal women. Journal of Clinical Endocrinology and Metabolism $1996814492-4495$.

6 Saitoh H, Kamoda T, Nakahara S, Hirano T \& Nakamura N. Serum concentrations of insulin, insulin-like growth factor (IGF)I, IGF binding protein (IGFBP)-1 and -3 and growth hormone binding protein in obese children: fasting IGFBP-1 is suppressed in normoinsulinaemic obese children. Clinical Endocrinology 1998 48 487-492.

7 The Expert Committee on the Diagnosis and Classification of Diabetes Mellitus. Report of the expert committee on the diagnosis and classification of diabetes mellitus. Diabetes Care 199720 1183-1197.

8 Haffner SM, Stern MP, Hazuda HP, Pugh JA \& Patterson JK. Hyperinsulinemia in a population at high risk for non-insulindependent diabetes mellitus. New England Journal of Medicine 1986 315 220-224.

9 Amiel SA, Sherwin RS, Simonson DC, Lauritano AA \& Tamborlane WV. Impaired insulin action in puberty. A contributing factor to poor glycemic control in adolescents with diabetes. New England Journal of Medicine 1986315 215-219

10 Bloch CA, Clemons P \& Sperling MA. Puberty decreases insulin sensitivity. Journal of Pediatrics $1987110481-487$.

11 Traverse SH, Jeffers BW, Blooch CA, Hill JO \& Eckel RH. Gender and Tanner stage differences in body composition and insulin sensitivity in early pubertal children. Journal of Clinical Endocrinology and Metabolism 199580 172-178.

12 Lee PDK, Conover CA \& Powell DR. Regulation and function of insulin-like growth factor-binding protein-1. Proceedings of the Society for Experimental Biology and Medicine 1993204 4-29.

13 Brismar K, Grill V, Efendic S \& Hall K. The insulin-like growth factor binding protein-1 in low and high insulin responders before and during dexamethasone treatment. Metabolism $199140728-$ 732 .

14 Hellénius MB, Brismar KE, Berglund BH \& De Faire UH. Effects of glucose tolerance, insulin secretion, insulin-like growth factor 1 and its binding protein, IGFBP-1, in a randomized controlled diet and exercise study in healthy, middle-aged men. Journal of Internal Medicine 1995238 121-130.

15 Reaven GM, Moore J \& Greenfield M. Quantification of insulin secretion and in vivo insulin action in nonobese and moderately obese individuals with normal glucose tolerance. Diabetes 1983 32 600-604.

16 Morris DV \& Falcone T. The relationship between insulin sensitivity and insulin-like growth factor-binding protein-1. Gynecological Endocrinology 199610 407-412.

Received 14 July 1998

Accepted 27 November 1998 